\title{
Estimating Technical Efficiency of Chinese Table Grape Wholesalers
}

\author{
Weihua Jiao, Weisong Mu, Xiaoshuan Zhang, Jianjun Lu and Zetian Fu \\ China Agricultural University, Beijing, People's Republic of China \\ Mark Xu \\ University of Portsmouth, Portsmouth, UK
}

\begin{abstract}
Purpose - This research aims to estimate the technical efficiency of Chinese table grape wholesalers and subsequently to examine the degree to which the calculated efficiency correlates with a set of explanatory variables.
\end{abstract}

Design/methodology/approach - A two-stage procedure is applied in this paper. First, a non-parametric data envelopment analysis (DEA) technique is applied to investigate the degree of technical efficiency for Chinese table grape wholesalers. Secondly, Tobit regression is used to analyze the factors influencing technical efficiency.

Findings - Research results reveal that the mean technical efficiency of the sample is 0.544 and 0.860 under CRS and VRS assumptions, respectively, and the scale efficiency is 0.620 . The variables of experiences, number of grape varieties on sale, daily selling volumes and fixed sale ratio have a significant effect on technical efficiency, whilst the other exogenous variables do not affect the efficiency in any significant way.

Research limitations/implications - The findings of this research are specific to table grape wholesalers in China, however, the method used in this study is transferrable and applicable to the study of similar problems in others countries.

Originality/value - This research has yielded some interesting and original insights into the efficiency level of Chinese grape wholesalers and the factors that influence the level of efficiency. The findings have practical implications for Chinese agriculture policy makers, and are able to stimulate further research of a similar type in the international agricultural research community.

Key words Table grapes, China, Wholesaler, Technical efficiency, DEA, Tobit, Influencing factors Paper type Research paper

\section{Introduction}

Table grape is one of the most important horticultural crops in China. According to the United States Department of Agriculture, China has been ranked first in the world for table grape production over the last five years (USDA, 2014). In China, rising income and a move towards urban lifestyles has led to dietary shifts away from staples (e.g. rice and flour) towards vegetables, fruit, and dairy products (Stringer et al., 2009), and accordingly, table grape consumption is expected to increase along with that of other fruits in coming years. In addition, table grape cultivation and sale is very labor intensive and provides substantial employment opportunities, not only in production but also in transportation and marketing. China is still a developing country and has a comparative advantage in labor-intensive industries, thus it becomes of paramount importance for China to develop the table grape industry with appropriate strategies and technologies.

Consumer demand for perishable agricultural produce in China has changed significantly over recent years. The supply of fruit has become abundant and competition is fierce due to increased local and international production. Consumers demand higher quality, more variety products than ever before (Meulenberg, 2000). The retail sector for agricultural products has developed in 
parallel with overall economic development. As it constitutes the marketing element in the supply chain, this retail transformation has also significantly changed the wholesale sector and the conditions faced by farmers. The rise of supermarkets has been swift and extensive in China over the past decade, growing from a minor retail segment in the 1990s to a 50\% share of the national retail sector (National Bureau of Statistics of China, 2014). This rise has deeply transformed supply chain at different rates and depths across regions and countries, as supermarkets have indeed related impacts 'upstream' in the agrifood system, on farmers, wholesalers, and first-stage processors (Reardon et al., 2002). A growing number of retailer-leading supply chains have emerged that attract researchers' attention.

China has more than 4,000 wholesale agrifood markets, and transactions in wholesale markets account for about 70 percent of the distribution of agricultural products (Li et al., 2013). Unlike in most European and American countries, the wholesale agrifood markets are the hub of agricultural supply chains in China (Chen, 2006; Han et al., 2010), including those for table grapes (Jiao et al., 2012). The wholesale markets drive the flow of table grapes towards the final consumers by means of their intermediate position between the viticulture sector and the retail sector in the distribution channel. Recent research (Liu et al., 2010) suggests that the wholesale agrifood market plays a key role in the distribution of table grapes by means of adjustment of demand and supply, commercial function, price discovery and creation of distribution information.

Moreover, the role of wholesaling in the agricultural product supply chain is not simply one of pass-through, as the efficiency of this link has a major impact on the remainder of the chain, including vinegrowers, distributors, retailers and consumers. In China, small-scale vinegrowers dominate the table grape production system and hence constitute a very important part of the industry. The principle concern of vinegrowers is how well the grapes are marketed to consumers. Currently there are many small-scale vinegrowers for whom the marketing channels available are rather limited. Meanwhile, the characteristics of small-scale family agriculture, with a wide diversity of cultivars and yields resulting in high search costs for purchasers, complicates matters for retailers, especially for supermarkets who have diversified requirements and large demand. As a result, intermediaries - wholesalers - have emerged as a channel by which grapes move from vineyard to retailing sector. As the hub of the supply chain, wholesalers assume responsibilities of working closely with the other members to ensure that retailers provide consumers with high quality grapes and vinegrowers operate efficiently with minimal market risk. Research (Wang, 2007; Zhao, 2009) suggests that the Chinese wholesale agrifood market has been growing, but the level of efficiency of wholesale market falls behind benchmarks set by developed regions and countries. This has restricted the improvement of circulation efficiency, as a result, Chinese policy makers pay increased attention on improving the performance of the wholesale market, for example, since 2004, the Chinese central government has adopted a series of policies and measures to reform and upgrade the agricultural products wholesale market, with the aim of developing an efficient distribution system of agricultural products (Ministry of Agriculture of the People's Republic of China Net, 2011).

Recent literature concerning the wholesale agrifood market can be classified into five categories. The first category focusses on the structure and trend of wholesale agrifood market (see, for example, Ahmadi-Esfahani et al., 1998; Jin et al., 2007; Liu et al., 2011; Li et al., 2013).

Ahmadi-Esfahani et al. (1998) explored some of the issues of wholesale agrifood markets in China, in particular, the evolutionary structure of wholesale agrifood markets. Jin et al. (2007) and 
Liu et al. (2011) discussed the trend of the agricultural products wholesale market in China, for which a new operation type of wholesale agrifood market was analyzed by Li et al. (2013). The second category is research devoted to analyzing the function of the wholesale agrifood market (Lee et al., 2002; Ren et al., 2010). Lee et al. (2002) analyzed the improvement of pricing efficiency in wholesale fish markets by applying the framework of the price decision support system, whilst Ren et al. (2010) analyzed the food safety control function of the wholesale agrifood market in China. Thirdly, some researchers have sought to analyze the behaviors of, and outcomes for, participants in wholesale agrifood markets, for example, behavior change (Giulioni et al., 2011; Gallegati et al., 2011), price dispersion (Fluvià et al., 2012), price discrimination (Graddy et al., 2009), price formation (Kirman et al., 2002; Guillotreau et al., 2006; Vignes et al., 2011; Guillotreau et al., 2011; Gobillon et al., 2013), price dynamics (Giulioni et al., 2008) and price discovery (Ahmadi-Esfahani et al., 1998). In the fourth group, the issue of evaluating the performance of wholesale agrifood market has been reported (Zhu, J. 2006; Kim et al., 2009; Zhang et al., 2009). The performance of the wholesale market is often evaluated from four aspects: scale, finance, customer satisfaction and the administrators. Finally, there are also studies reporting on the integration of the wholesale agrifood market. For example, Mukhtar et al. (2008) tested long-run spatial market integration between price pairs of maize in four regional markets of Pakistan using a co-integration and Error-Correction Model (ECM) approach.

With the exception of Kou et al.'s (2008) study on the technical efficiency of vegetable wholesalers and factors influencing this in China, very little attention has been paid, from a microscopic perspective, to the operation and performance of agricultural products wholesalers. As a key business operator in the supply chain, wholesalers could reduce the transaction cost between vinegrowers and retailers and thus improve the overall distribution efficiency (Han et al., 2010). Hence, the efficiency of wholesalers is vital to the overall distribution efficiency. Chinese agricultural product wholesalers tend to operate business on a small scale. What is the level of wholesalers' efficiency and what factors might affect their efficiencies? These questions deserve more attention from both researchers and policy makers.

Technical efficiency in a production unit refers to the achievement of the maximum potential output from given amounts of inputs, taking into account physical production relationships (Iráizoz et al., 2003). Early studies on technical efficiency mainly focused on crop farming and animal husbandry. The scope of technical efficiency research has expanded to other sectors, e.g. the financial sector (e.g. Paxton, 2007; Pasiouras, 2008; Liu, 2010), education sector (e.g. Giménez et al., 2007; Conroy et al., 2008) and service sector (e.g. Herr, 2008; Perrigot et al., 2008; Sellers-Rubio et al., 2009). In this paper, technical efficiency is defined as the ratio of a table grape wholesaler's actual outputs to the theoretical profit boundary representing the best a wholesaler can achieve with given input resources. This ratio reflects the ability of a table grape wholesaler to obtain outputs from a given set of inputs. Farrell's innovative article (Farrell, 1957) led to the development of several approaches to efficiency assessment. These approaches can be classified into two broad categories: parametric and non-parametric frontier models. The former requires the assumption of a functional form to be made for the production frontier, and estimates the coefficients of the production function and technical efficiency statistically. On the other hand, the latter constructs a linear piecewise function from empirical observations of inputs and outputs based on mathematical programming, and therefore, does not specify functional relationships between inputs and outputs. In contrast to parametric model, the non-parametric one has the 
advantage that it avoids the need to make assumptions concerning the functional form for the production function. Thus, the non-parametric frontier model is preferred in this study.

Most non-parametric applications are based on the Data Envelopment Analysis (DEA) model as proposed by Charnes et al. (1978). The DEA model has become one of the main techniques for efficiency analysis and has been widely applied in economics and management sciences. As an important and useful economic measure of organizational performance, DEA has been used in assessing the efficiency of a variety of organizations, such as government (Balaguer-Coll et al., 2007), firm (Gillen et al., 1997) , farm (Hansson et al., 2008), and so on. The DEA model is adopted in this study and the details are discussed next.

In addition to estimating the technical efficiency of wholesalers, another important question is whether it is possible to determine common characteristics among best practice units. It is essential to identify the sources of efficiency change in order to develop policies to improve wholesalers' performance. Therefore, this paper also examines statistically the factors influencing wholesalers' technical efficiency. The focus will be on assessing the relationship between technical efficiency and several operational characteristics of table grape wholesaling.

Taking into account the considerations described above, the specific objectives of this study are as follows: first, to calculate the technical efficiency of table grape wholesalers; second, to identify important factors that cause technical efficiency differences among wholesalers; third, to infer policy implications based on efficiency scores and the factors that influence them.

\section{Methodology}

\subsection{The sampling}

This paper analyses the technical efficiency of table grape wholesalers in China using a sample obtained from Beijing. As the capital of China, Beijing is a metropolis and had a population of 20.69 million by the end of 2012. According to the Beijing Statistics Yearbook 2013, the total consumption of fruit in Beijing reached more than 8 million tonnes in 2012 (Beijing Statistical Information Net). The consumption of table grapes has increased significantly in Beijing in recent years due both to a substantial increase in citizens' disposal income and increased health awareness. A considerable proportion of table grape is pushed by wholesalers along the distribution channel to consumers every year.

This study was conducted within five wholesale agrifood markets located in various parts of the city in 2010. They are Xinfadi, Shunxinshimen, Jinxiudadi, Baliqiao and Shuitun, which provide the majority of fruit consumption for Beijing.

\subsection{Model specification}

In this research, the table grape wholesaler is identified as a production unit. While in the process of wholesale, the inputs of wholesalers include labor, capital, time, information and equipment, and the outputs are service, information and benefit (as shown in Fig 1). The wholesalers firstly purchase table grape $\mathrm{Q}_{1}$ (quantity) with the value of $\mathrm{V}_{1}$ from vinegrowers at the time of $T_{1}$, and then sell the $Q_{2}$ (quantity) table grape with the value of $V_{2}$ at the time of $T_{2}$. Since table grapes have a short shelf life and are highly perishable, the wholesalers would need to sell their stock in the shortest possible time to minimize losses from spoilage, and of course sell them at the highest possible price in the market. Their expectation is to minimize $\mathrm{Q}_{1}-\mathrm{Q}_{2}$ and $\mathrm{T}_{2}-\mathrm{T}_{1}$ and maximize $\mathrm{V}_{2}-\mathrm{V}_{1}$. However, the efficiency of wholesalers varies, as it is affected by a number of factors, including wholesalers' individual characteristics, their operating activities, the socio-economic environment and the partnership between wholesalers and their traders. 


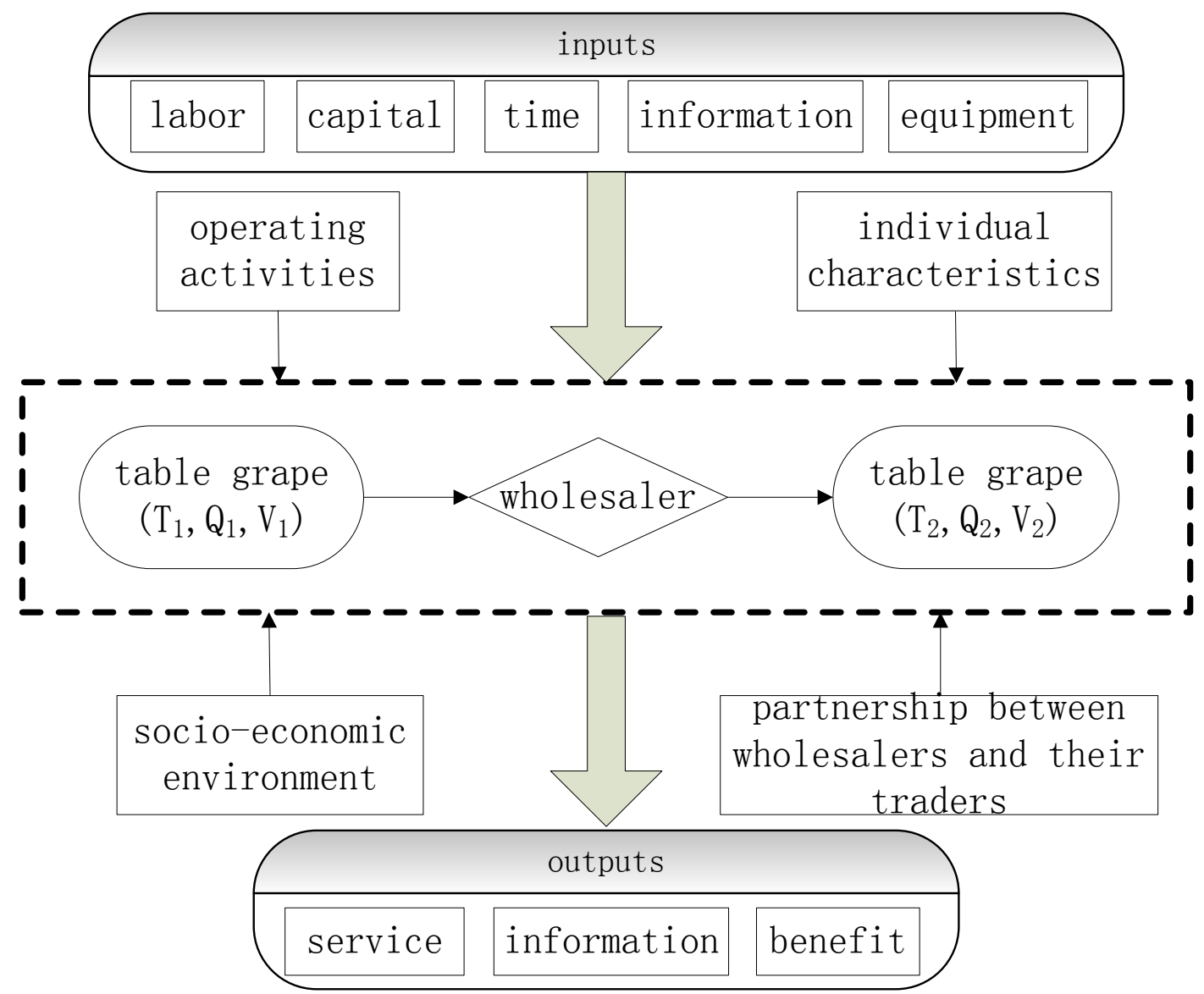

Fig 1 Wholesale process for table grape

The methodology used in this study is a two-stage process commonly used in the efficiency literature. The efficiency scores of the wholesaler are estimated in a first step, and then the scores are used as dependent variables in a second-stage regression which sought to evaluate the factors influencing technical efficiency.

\subsubsection{DEA model}

The DEA model applied in this paper is originated from the seminal work on technical efficiency by Farrell (1957). This model is a linear programming technique for evaluating the relative performance of each decision-making unit (DMU, in our case table grape wholesalers) based on observed data, thereby allowing a distinction to be made between efficient and inefficient units. The units which determine the frontier are identified as "best practice units" and given a rating of one, whereas the degree of the technical inefficiency units is calculated on the basis of the Euclidian distance of their input-output ratio from the frontier (Coelli et al., 1998).

Technical efficiency represents the ability of a DMU to produce the maximum feasible output from a given bundle of inputs or, alternatively, to use minimum feasible amounts of inputs to produce a given level of output. These two definitions of technical efficiency lead to what are, respectively, known as "output-oriented" and "input-oriented" efficiency measures (Coelli et al., 2002). The choice between the two measures is a matter of concern, and selection may vary according to the unique characteristics of the DMUs under study. The input-oriented DEA model is used in this paper, given that it is reasonable to argue that a wholesaler has more control over their inputs than outputs, which may often be exogenously bounded. 
The DEA model is presented here for a case where there is data on $M$ inputs and $N$ outputs for each of the $K$ wholesalers. The model to calculate the technical efficiency is represented by the linear programming problem (Coelli et al., 1998):

$$
\begin{array}{ll}
\operatorname{Min}_{\theta, \lambda} & \\
\text { subject to } & -y_{i}+Y \lambda \geq 0 \\
& \theta x_{i}-X \lambda \geq 0 \\
& K 1^{\prime} \lambda=1 \\
& \lambda \geq 0
\end{array}
$$

where:

$\theta$ is a scalar with boundaries of zero and one;

$\lambda$ is the $K \times 1$ vector of constants;

$y_{i}$ is the column vector of outputs for the $i-t h$ wholesaler;

$Y$ is the $N \times K$ output matrix;

$x_{i}$ is the column vector of inputs for the $i-t h$ wholesaler;

$X$ is the $M \times K$ input matrix;

$K 1$ is the $K \times 1$ vector of ones.

In order to obtain efficiency scores for each wholesaler, the model has to be solved once for each wholesaler. Using the variables $\lambda$ and $\theta$, Eq. (1) has to be solved $K$ times, looking for the largest radial contraction of the input vector ${ }^{x_{i}}$ within the technology set. The value of $\theta$ corresponding with this contraction is the technical efficiency score for the $i-t h$ wholesaler. A value of $\theta=1$ indicates that a wholesaler is technically efficient and $\theta \prec 1$ indicates technically inefficiency. $K 1^{\prime} \lambda=1$ is a convexity constraint that creates a variable returns to scale (VRS) specification of the model. Without this convexity constraint, Eq. (1) makes up the constant returns scale (CRS) specification. A key limitation of the CRS model is its assumption that all observed wholesalers operate at the optimal scale (Fraser et al., 1999). However, in the case of wholesale, increased amounts of inputs do not proportionately increase the amount of outputs. For example, when the amount of labor is increased, a linearly proportional increase in wholesale benefit is not necessarily obtained. Therefore, in addition to the CRS efficiency scores $\left(T E_{C R S}\right)$, the VRS efficiency scores $\left(T E_{V R S}\right)$ are estimated in this paper. Additionally, a comparison of both scores is interesting because it provides information on scale efficiency ( $S E$ ), 
which can be used to determine how closely an observed wholesaler is to the most productive scale size. The relation is expressed in the equation as follows: $\mathrm{SE}=\mathrm{TE}_{\mathrm{CRS}} / \mathrm{TE}_{\mathrm{VRS}}$. Although critical, the degree of SE is not very useful from a managerial point of view, unless one can determine whether a wholesaler is operating in a region where decreasing (DRS) or increasing (IRS) returns to scale exist. This information could be obtained if the convexity constraint $K 1^{\prime} \lambda=1$ in Eq. (1) is substituted with $K 1^{\prime} \lambda \leq 1$, thereby allowing both for constant and decreasing (i.e. non-increasing) returns to scale (NIRS). If the two scores of $T E_{C R S}$ and $T E_{V R S}$ are equal then DRS applies; else IRS prevails (Galanopoulos et al., 2006).

As mentioned earlier, the most notable feature of the DEA model is that it allows for comparative evaluation of wholesaling performance. In addition to separating the efficient wholesalers from the inefficient ones, this model is able to compute the efficient input levels for inefficient wholesalers in terms of linear combinations of input and output levels of efficient ones, and thus show reductions of input (input slack) for the inefficient ones. Efficiency measures under CRS and VRS are calculated by using DEAP 2.1 by Coelli (1996).

\subsubsection{Tobit model}

After calculating the efficiency measures, the next step is to identify the factors influencing technical efficiency, which is commonly done by estimating a second-stage relationship between the efficiency measures and suspected correlates of efficiency. This study attempts to explain variations in efficiency scores by regressing these scores on certain explanatory variables. Since the efficiency parameters vary between zero and one, they are censored variables and thus a Tobit regression model with lower limits is appropriate (Galanopoulos et al., 2006). The applied model is specified as follows (Greene, 2002):

$$
y_{i}^{*}=x_{i} \beta+u_{i} \quad \text { with the observed data } y \text { given by: } \quad \mathrm{y}_{\mathrm{i}}=\left\{\begin{array}{ccc}
0 & \text { if } & y_{i}^{*} \leq 0 \\
y_{i}^{*} & \text { if } \quad y_{i}^{*} \succ 0
\end{array}\right.
$$

where:

$y_{i}^{*}$ is the latent variable;

$x_{i}$ denotes the vector explanatory variables;

$\beta$ denotes the relationship between the latent and the explanatory variables;

$u_{i}$ is random error which normally distributed with mean zero and variance $\sigma^{2}$.

\subsection{Data and description of variables}

The data used for this study was collated from structured interviews with 91 table grape wholesalers in Beijing from May 2010 to September 2010, a period that covers the main production and marketing period of table grapes in China.

2.3.1 Variables for calculating technical efficiency

In this study, wholesalers' gross profit is selected as the output variable. Allowing for the main production and marketing period of table grape in China, output is measured as the wholesaler's 
monthly gross profit. For the input variables, four values are collected: circulating capital, fixed assets, labor and market stall. Circulating capital and fixed assets are selected as proxies for total capital input and measured in Chinese currency (RMB). Circulating capital refers to the aggregate money used to maintain the daily operation of the wholesaler, while fixed assets represent the total value of wholesale facilities, including automobiles, refrigeration equipment and so on. Labor, including the employee and wholesaler's family members, is selected as a proxy for labor input, while market stall used for wholesaling is measured in monthly rent (Chinese currency -RMB).

It is required that the correlation between inputs and outputs is in the same direction. Therefore, the correlation between inputs and outputs was assessed by using Pearson correlation statistics. The variables should be wiped out if the 2-tailed test is not significant. There is a strong correlation between four input variables and an output variable, as shown in Table 1, which indicates that the variables selected meet the requirement of DEA.

Table 1 Correlation analysis of input variables and output variables

\begin{tabular}{cccccc}
\hline & $\mathrm{Y}$ & $\mathrm{X}_{1}$ & $\mathrm{X}_{2}$ & $\mathrm{X}_{3}$ & $\mathrm{X}_{4}$ \\
\hline $\mathrm{Y}$ & 1.000 & & & & \\
$\mathrm{X}_{1}$ & $0.885^{* *}$ & 1.000 & & & \\
$\mathrm{X}_{2}$ & $0.680^{* *}$ & $0.574^{* *}$ & 1.000 & & \\
$\mathrm{X}_{3}$ & $0.592^{* *}$ & $0.451^{* *}$ & $0.617^{* *}$ & 1.000 & \\
$\mathrm{X}_{4}$ & $0.847^{* *}$ & $0.939^{* *}$ & $0.527^{* *}$ & $0.387^{* *}$ & 1.000 \\
\hline
\end{tabular}

**. Correlation is significant at the 0.01 level (2-tailed).

The output variable is $\mathrm{Y}$, while input variables include $\mathrm{x}_{1}, \mathrm{x}_{2}, \mathrm{x}_{3}$ and $\mathrm{x}_{4}$.

\subsubsection{Variables for identifying factors influencing technical efficiency}

Technical inefficiency in the wholesale process is attributed to a number of events that would unfavorably affect the wholesalers' capacity to transform input resources into output. Some of the undesirable events are beyond wholesalers' control, such as war, disasters, weather and policy changes. Nevertheless, others could be ascribable to wholesalers themselves and thus could be amended. The variables included in the Tobit analysis can be divided into three groups: individual characteristics of wholesalers, operating activities of wholesalers and the partnership between wholesalers and their traders. As for the nine explanatory variables which are deemed to indirectly affect the technical efficiency of table grape wholesalers, their definitions and expected signs are presented in Table 2 .

The age and education level variables reflect on individual characteristics of table grape wholesalers. The age of the wholesaler may suggest a higher operating capability of wholesaling is available, and thus the impact on efficiency could be positive. The education variable served to test the hypothesis that a higher level of education can lead to a better assessment of the complexities of wholesale decisions and thus can lead to better wholesale practices and efficiency. The anticipated impact of education on efficiency is therefore positive. Education level is measured in length of time spent in education.

To explore the relationship between technical efficiency and the operating activities of wholesalers, a number of variables are included in the model including: their experiences, information acquiring abilities, the number of grape varieties on sale, daily selling volumes and market stall area. The experiences variable is measured in time they have spent in the table grape wholesaling business, and a lack of experiences is considered as potential source of technical 
inefficiency. It is anticipated that the impact of experiences on efficiency is positive. Information acquiring abilities denote the extent to which wholesalers can access information on grape wholesaling. More information means the wholesalers have an accurate grasp of varieties and price (i.e. purchase and sale price), and thus the impact of information acquiring abilities is expected to be positive. The score of information acquiring abilities is measured as follows: firstly, the most common ways for wholesalers to access information are selected, including management department of wholesale market, friends, counterparts, television and internet; secondly, the degree of accessing information is divided into three levels, which correspond to 0,1 and 2 from low to high, respectively; lastly, information acquiring abilities are the summation of scores for each way. In this study, the scores of information acquiring abilities range from 0 to 10 . The number of grape varieties on sale and daily selling volumes represent the level of wholesaler's service. It is considered that the wholesaler would achieve a high level of service if they are able to provide more varieties and higher quantities of grapes for customers. A higher level of service to customers can lead to better customer satisfaction, hence, the impact of service level is expected to be positive. A larger market stall area means more space for wholesaling, and so makes it easier for the wholesalers to expand their operating scale and thereby increase service levels. As a result, a larger market stall area is considered to lead to more efficient operation and the impact of market stall area is expected to be positive.

Wholesalers' traders include not only the upstream suppliers but also the downstream customers. Fixed supply and sale ratios are selected so as to capture the impact of the partnership between wholesalers and their traders on technical efficiency. Fixed supply (sale) ratio denotes the percentage of grapes supplied (bought) by fixed suppliers (customers) on all grapes supplied (sold). A larger percentage means that the wholesaler has more reliable suppliers and marketing channels, and thus the anticipated impact of partnership on efficiency is positive.

Table 2 Definition of explanatory variables and their expected signs

\begin{tabular}{cccc}
\hline Variable & Name & Unit & Expected sign \\
\hline age of wholesaler & age & year & + \\
education level of wholesaler & education level & year & + \\
wholesaler's experiences & experience & year & + \\
number of grape variety on sale & grape variety & number & + \\
information acquiring ability & ability & - & + \\
market stall area & area & $\mathrm{m}^{2}$ & + \\
daily selling volumes & selling volume & ton & + \\
fixed supply ratio & fixed supply ratio & $\%$ & + \\
fixed sale ratio & fixed sale ratio & $\%$ & + \\
\hline
\end{tabular}

\section{Results and discussion}

Table 3 presents the descriptive statistics for the variables used in the analyses. A wide variation of value exists in the variables. Taking the variables of input and output as an example, some wholesalers have 25 times more circulating capital and monthly rent of market stall than others, whereas variation in fixed assets and labor are around 6 times. While variation in output variables is even higher, the output obtained is in some cases 30 times larger than that achieved by other wholesalers. Thus, there is a large difference in terms of business scale among the sample of 
wholesalers and this is likely to be mirrored in the efficiency scores. Likewise, as shown in Table 3 , the sample is heterogeneous when it comes to the factors influencing wholesale efficiency. Such a variation in the influencing factor levels certainly suggests that wholesale efficiency would be influenced by certain events to some extent.

Table 3 Descriptive statistics of input and output measures and of the variables

\begin{tabular}{|c|c|c|c|c|c|}
\hline Variables & Unit & Min & Max & Mean & SD \\
\hline \multicolumn{6}{|l|}{ output } \\
\hline $\begin{array}{l}\text { monthly gross profit } \\
\text { inputs }\end{array}$ & yuan & 6000.00 & 180000.00 & 31572.86 & 34327.15 \\
\hline circulating capital & yuan & 8000.00 & 200000.00 & 40613.72 & 35105.31 \\
\hline market stall & yuan & 300.00 & 7500.00 & 2640.69 & 1103.33 \\
\hline labor & person & 1.00 & 6.00 & 2.86 & 1.22 \\
\hline fixed assets & yuan & 466.00 & 2768.00 & 1039.27 & 507.48 \\
\hline \multicolumn{6}{|c|}{ variables for identifying factors that influence technical efficiency } \\
\hline age of wholesaler & year & 20 & 60 & 37.81 & 9.34 \\
\hline education level of wholesaler & year & 0 & 12 & 7.62 & 3.27 \\
\hline wholesaler's experiences & year & 1 & 20 & 6.94 & 4.35 \\
\hline number of grape variety on sale & number & 1 & 6 & 2.95 & 1.06 \\
\hline information acquiring ability & - & 1 & 10 & 3.91 & 2.50 \\
\hline market stall area & $m^{2}$ & 8 & 40 & 15.68 & 7.83 \\
\hline daily selling volumes & ton & 0.5 & 10 & 1.73 & 1.92 \\
\hline fixed supply ratio & $\%$ & 0 & 1 & 0.36 & 0.40 \\
\hline fixed sale ratio & $\%$ & 0 & 0.9 & 0.52 & 0.29 \\
\hline
\end{tabular}

\subsection{Technical efficiencies of table grape wholesalers}

\subsubsection{Distribution of technical efficiencies}

Results obtained by the application of the input-orientated DEA are illustrated in Table 4. Ten wholesalers (11\%) are operating at best practice under CRS. However, the distribution of scores shows that only eight wholesalers $(8.8 \%)$ are very close to the optimum level of wholesaling. The mean radial technical efficiency of the sample is 0.544 under CRS assumptions and the overall efficiency range from 0.158 to 1 . This implies that on average, wholesalers could reduce their inputs by $45.6 \%$ and still maintain the same output level, and also that there is considerable variation in the performance of table grape wholesalers.

Deconstruction of the technical efficiency measure shows that scale inefficiency is the primary cause of technical inefficiency. Scale efficiency averaged 0.620 and an additional 38\% productivity gain would be feasible, assuming no other constraining factors. Only ten wholesalers (11\%) are actually operating at the most productive scale where CRS applies and scale efficiency equals one. $86.81 \%$ of the total sample of wholesalers are operating under increasing returns to scale (IRS), indicating that when these wholesalers expand their input levels by a certain percentage, their output levels would expand by a larger percentage. Efficiency analysis theory suggests that these are obviously small wholesalers and need to increase their size in order to achieve cost savings. Only two wholesalers (2.5\% of the inefficiency wholesalers) are operating under decreasing returns to scale (DRS). This implies that the majority of table grape wholesalers 
in Beijing are far from the optimal size, thus expanding wholesalers' scale could lead to improved efficiency.

The analysis reveals that the average pure technical efficiency (i.e. $T E_{V R S}$ ) of the sample wholesalers is very high, with an average of 0.860 . This is contributed by the vast majority of wholesalers $(94.5 \%)$ whose pure technical efficiency is between 0.600 and 1.The reason for this may be that the wholesale business is easier to operate than viticulture itself, where complex issues to manage include pest and disease control, irrigation management, canopy management, fertilization management and pesticide application.

Table 4 Distribution of technical efficiencies for a sample of table grape wholesalers

\begin{tabular}{ccccccc}
\hline & \multicolumn{2}{c}{$T E_{C R S}$} & \multicolumn{2}{c}{$T E_{V R S}$} & \multicolumn{2}{c}{$S E$} \\
score value & \multicolumn{1}{c}{ sample } & percentag & sample & percentage & sample & percentage \\
& number & e $(\%)$ & number & $(\%)$ & number & $(\%)$ \\
\hline $0 \leq \mathrm{TE}<10 \%$ & 0 & 0 & 0 & 0 & 0 & 0 \\
$10 \% \leq \mathrm{TE}<20 \%$ & 2 & 2.20 & 0 & 0 & 0 & 0 \\
$20 \% \leq \mathrm{TE}<30 \%$ & 20 & 21.99 & 0 & 0 & 9 & 9.89 \\
$30 \% \leq \mathrm{TE}<40 \%$ & 14 & 15.38 & 0 & 0 & 13 & 14.29 \\
$40 \% \leq \mathrm{TE}<50 \%$ & 8 & 8.79 & 1 & 1.10 & 11 & 12.09 \\
$50 \% \leq \mathrm{TE}<60 \%$ & 10 & 10.99 & 4 & 4.40 & 14 & 15.38 \\
$60 \% \leq \mathrm{TE}<70 \%$ & 10 & 10.99 & 16 & 17.58 & 8 & 8.79 \\
$70 \% \leq \mathrm{TE}<80 \%$ & 9 & 9.89 & 8 & 8.79 & 10 & 10.99 \\
$80 \% \leq \mathrm{TE}<90 \%$ & 4 & 4.40 & 11 & 12.09 & 10 & 10.99 \\
$90 \% \leq \mathrm{TE}<100 \%$ & 4 & 4.40 & 19 & 20.88 & 6 & 6.59 \\
$\mathrm{TE}=100 \%$ & 10 & 10.99 & 32 & 35.16 & 10 & 10.99 \\
average & & 0.544 & & 0.860 & & 0.620 \\
\hline
\end{tabular}

\subsubsection{Comparative analysis of technical efficiency for different wholesale markets}

Table 5 Distribution of technical efficiencies for different wholesale markets

\begin{tabular}{cccc}
\hline wholesale market & $T E_{C R S}$ & $T E_{V R S}$ & $S E$ \\
\hline Xinfadi & 0.590 & 0.883 & 0.653 \\
Jinxiudadi & 0.463 & 0.832 & 0.542 \\
Shunxinshimen & 0.553 & 0.854 & 0.632 \\
Shuitun & 0.534 & 0.850 & 0.607 \\
Baliqiao & 0.533 & 0.863 & 0.623 \\
\hline
\end{tabular}

Table 5 presents the distribution of efficiency scores across the five study sites. Wholesalers located in Xinfadi are the most technically efficiency units, whereas Jinxiudadi has the least efficient wholesalers. There are two possible reasons for this result. First, Xinfadi is the largest wholesale market in China, supplying the majority of fruit consumed by people in Beijing and having a location which is easier to access than its rivals. Second, the Xinfadi wholesale market has the most modern facilities of any wholesale market in Beijing. According to the results of this research, the Xinfadi wholesale market has become the preferred choice for many large 
supermarkets in Beijing. In contrast, Jinxiudadi is not only smaller in scale but is also located close to Xinfadi, which makes it less favorable for customers. Therefore it is no surprise to see the lowest efficiency from the Jinxiudadi wholesale market. The gaps between the other three wholesale markets are not significant.

\subsubsection{Optimization analysis of technical efficiency for table grape wholesaling}

One of the most notable features of DEA is that it can provide useful information and evidence for a managerial evaluation of all DMUs separately, thereby identifying and assessing the exact sources of inefficiencies for each DMU. This process enables a wholesaler to highlight where the greatest gains can be made from improvements in efficiency and help them to achieve their full potential (Abbott et al., 2003). As an illustration, we choose the case of a technically inefficient wholesaler in the sample, which is DMU13. For this analysis we look at the results obtained by the VRS DEA model, as only a small fraction of the wholesalers in the sample are operating at an

optimal scale (11\% of the wholesalers). $T E_{V R S}$ for DMU13 is 0.622 , implying that the wholesaler could become technically efficient (under the Farrell definition) provided it reduced all its inputs proportionally by $37.8 \%$. Hence, the analysis suggests that input use could be reduced to those shown in the third row of Table 6 while maintaining current production levels, assuming no other constraining factors. However, a further slack adjustment is necessary if this wholesaler is to become Pareto-efficient. Ultimately, DMU13 has to reduce all inputs by $37.8 \%$, and circulating capital and market stall costs by another $3.6 \%$ and $13.3 \%$ (as shown in the fifth row of Table 6), respectively, in order to be operating at a fully technically efficient point.

Table 6 Actual and efficient input use levels of DMU13

\begin{tabular}{ccccc}
\hline & \multicolumn{4}{c}{ Inputs } \\
\cline { 2 - 5 } & circulating capital (yuan) & market stall (yuan) & labor (person) & fixed assets (yuan) \\
\hline actual values & 26565.00 & 2760.00 & 2.00 & 840.00 \\
radial movement & -10044.40 & -1043.57 & -0.76 & -317.61 \\
projected point & 16520.6 & 1716.43 & 1.24 & 522.39 \\
slack adujustment & -954.00 & -367.86 & 0 & 0 \\
Pareto-efficient point & 15566.60 & 1348.57 & 1.24 & 522.39 \\
\hline
\end{tabular}

\subsection{Factors influencing technical efficiency}

In order to explain differences in the technical efficiency of wholesalers, we completed a regression analysis of the efficiency scores obtained from the DEA model against the vector of wholesale characteristics. The variables for identifying factors influencing technical efficiency are constructed using the data set described in the previous section and regressed on the scores of technical efficiency under CRS. The Tobit model is estimated by the maximum likelihood method. A "step by step" procedure is applied, including only those variables that proved to be statistically significant. The econometric package called EViews is used in this paper and the regression results are given in Table 7.

Table 7 Parameter estimates and standard error values of the inefficiency determinants for a sample of

wholesalers

\begin{tabular}{ccc}
\hline Variable & Coefficient & St. Error \\
\hline C & $0.178157^{* * * a}$ & 0.066643
\end{tabular}




$\begin{array}{ccc}\text { wholesaler's experiences } & 0.010212^{* c} & 0.006069 \\ \text { number of grape variety on sale } & 0.04267 *^{* c} & 0.02354 \\ \text { daily selling volumes } & 0.04271^{* * * a} & 0.013389 \\ \text { fixed sale ratio } & 0.181352^{* * \mathrm{~b}} & 0.084521 \\ \mathrm{R}^{2} & 0.426301 \\ \text { Adjusted } \mathrm{R}^{2} & 0.392554\end{array}$

\footnotetext{
${ }^{\text {a }}$ Significant at the $1 \%$.

${ }^{\mathrm{b}}$ Significant at the $5 \%$.

${ }^{\mathrm{c}}$ Significant at the $10 \%$.
}

The results presented in Table 7 shows that four variables affect technical efficiency in a significant way. In Table 7, a positive (negative) sign of a coefficient reflects a positive (negative) effect on efficiency levels. With that in mind, the par

ameter estimates show that the factors influencing technical efficiency include wholesaler's experiences, number of grape varieties on sale, daily selling volumes and fixed sale ratio, whilst the other exogenous variables do not affect technical efficiency in any significant way.

It is surprising to reveal that the effect of age is not significant. This may be explained in two ways. Firstly, age may not necessarily be a valid indicator of more operating capability of wholesaling since this variable does not necessarily capture wholesaling experiences. Secondly, table grape wholesaling is highly labor intensive and the time of wholesaling operation is mainly between 0:00 am and 9:00 am in our survey, which requires wholesalers to have high levels of physical strength and energy. Moreover, some of the wholesalers transport their supplies of table grapes. Therefore younger wholesalers may have a physical advantage over older ones and hence, the impact of age on efficiency is mixed and the coefficient is not significant.

With respect to wholesaler's education level, the insignificant coefficient rejects the hypothesis that a higher level of education can lead to a better wholesale practices, hence higher profit. The most likely reasons for this are as follows: the average schooling of wholesalers surveyed is 7.62 years, which may be adequate to the basic numeric accounting involved in the wholesaling business. Therefore, in the context of this sample and study, education level has no significant effect on technical efficiency.

The positive and significant coefficient on experiences indicated that a longer term of wholesaling business can lead to the acquisition of better managerial skills. This result suggests that table grape wholesaling is highly dependent on the experiences of wholesalers. For example, the wholesaler with more experiences is able to effectively organize the sources of table grapes according to the demand status of the crop in different periods.

Another outcome of the Tobit model is that the positive and significant effect of the number of grape varieties on sale and daily selling volumes implies that wholesalers with $\underline{a}$ better service level are more technically efficient. A higher level of service can better meet the needs of different consumers and cut their search cost, resulting in a long-term stable market relationship for the wholesaler. Large customers usually require a large quantity and a variety of table grapes, especially for supermarkets. In the Xinfadi wholesale market, a wholesaler with the efficiency score of 1.0 has supplied table grape to several supermarkets in Beijing for seven years. However, 
this finding is contradictory to Rawwas et al.'s (2008) assertion that the wholesalers' service to the buyer does not contribute to the performance of wholesalers. Much more research is needed in order to test the relationship between service level and wholesale efficiency.

Another surprising result is related to the factor of information acquiring ability. Contrary to prior expectations, the result is not significant, indicating that a higher level of ability to acquire information may not lead to better wholesale practices and higher efficiency. In this study, the wholesalers acquire information predominately in two ways: via the management departments of wholesale markets and via their counterparts. Whether or not wholesalers acquire information from other sources seems to hardly influence their business strategies and therefore information acquiring ability has no significant effect on technical efficiency.

The result on wholesalers' market stall area has an unexpected effect, i.e, a larger market stall appears not to increase the efficiency of a wholesaler. A possible explanation is that the size of market stall is always larger than needed. According to our survey, the average size of market stall is $15.68 \mathrm{~m}^{2}$ and in the overwhelming majority of cases, the full stall capacity is not fully utilized. Moreover, it appears that the position of market stall is more important than the size of the stall: a small market stall in a better position can have a larger customer flow volume than a larger stall in a poor position, thereby leading to higher profitability. For example, in the Jinxiudadi wholesale market, two wholesalers had stalls of a similar size. However, the wholesaler located at a crossroad gains higher efficiency than the one whose stall faces only one road.

The coefficient of fixed sale ratio implies that a better relationship between wholesalers and customers can improve the technical efficiency of wholesaler. This finding confirms the results of Carr et al. (1999) and Kannan et al. (2006) that successful partnerships in supply chains can significantly improve a member's financial performance. Better member relationships could help prevent fraudulent activities caused by information asymmetry and reduce transaction costs. Many studies, such as Somogyi et al. (2010), have shown that trust is a vitally important variable affecting the level of relationship quality. Therefore, to improve the relationship between wholesalers and other members in supply chain, action must be taken to improve the credibility and integrity of wholesalers.

As to the fixed supply ratio, the result is not expected, probably because wholesalers do not play a passive role in the relationship between suppliers and themselves during the period of our survey when the table grapes are in season in China.

\section{Policy recommendations}

The results of this research are of importance for the table grape wholesale sector in China. It seems that substantial increase in technical efficiency could be attained for table grape wholesalers by improving certain management practices. As far as strategy and policy development is concerned, the following suggestions could be put forth:

- Policy makers should focus on increasing the operating scale of wholesalers by providing them with easier access to finance and credit services. Wholesalers with more circulating capital can operate on a larger scale and provide diversified services. This enables them to gain access to supermarkets or other large-scale customers with large and continuous demand, and hence they can operate more efficiently. However, a lack of fund is the most serious challenge wholesalers are facing. In this study, more than $90 \%$ of wholesalers used to be farmers and as such they have not only a low economic status but also little access to 
credit. The strategy of providing wholesalers with better access to credit would require government support through an adequate legal and regulatory framework. A government supported program which reduces the transaction costs of providing credit to wholesalers would increase the scale of operations, thus improving wholesalers' performance.

- Policy makers should take effective measures to reduce the costs of wholesalers. This, in turn, will increase their capital for wholesaling and so potentially their scale of operations. According to our survey, excessive transportation fines and charges are posing particular difficulties for wholesalers. Therefore, the reduction of wholesaling cost could be achieved by implementing the green passage policy for fresh agricultural products and by reducing some taxes.

- Policy makers should build communication platform for wholesalers and other supply chain members so as to establish long-term and closer relationships between them. This would lead to not only a reduction of the wholesalers' transaction costs but also to reliable distribution channels of table grapes for wholesalers. For example, an online platform for supply and demand of table grape should be provided. Moreover, standard operations have to be guaranteed under government supervision.

\section{Concluding remarks}

The most common marketing channel for table grapes in China comprises networks of wholesalers that link smallholder vinegrowers and retailers, mainly ending in urban wholesale markets. Using a two-stage model technique based on empirical data collected in Beijing, this study addressed an important question: how can the level of wholesaling efficiency be improved?

Results suggest that on average, a potential $45.6 \%$ reduction in input use could be achieved with the same output level, assuming no other constrains on this adjustment. In addition, it reveals that the majority of table grape wholesalers operate on a small scale compared with the optimal size. As for the factors influencing technical efficiency, a number of operational factors including wholesaler's experiences, number of grape varieties on sale, daily selling volumes and fixed sale ratio are correlated with wholesaling efficiency. Based on these research findings, a number of policy recommendations were developed.

Wholesalers have promoted convergence between vinegrowers and retailers, hence an increasing role for them ought to be observed in Chinese table grape supply chains. This situation is likely to be replicated for wholesalers of other agricultural products in China. From this point of view we contend that some of the insights yielded by the analysis of table grape wholesaling may be carried over to the wholesale of other agricultural products in China, possibly yielding more general implications as to how the performance of the wider agrifood supply chain can be improved.

Other developing countries share similar characteristics with small-scale family agriculture, evolving consumer demand and limited marketing channels, where wholesalers often exist as the sole link between producers and retailers. Agricultural product wholesalers undoubtedly play a role in enabling such a large number of small-scale farmers to exist alongside a small number of retailers. A better understanding of the technical efficiency of Chinese wholesalers can offer lessons of great importance for these countries as their food economies develop. This serves to reinforce the idea that this paper yields valuable insights which may lead to further advances in the improvement of wholesale efficiency, well beyond the confines of the Chinese agrifood wholesale market. 
A limitation of this research is that it has been conducted in a specific context - table grape wholesalers in Beijing, nevertheless, the sample size is adequate for the analysis conducted. Future research following a similar approach, could be extended to other regions in China or to other countries.

\section{References}

Abbott, M. and Doucouliagos, C. (2003), "The efficiency of Australian universities: a data envelopment analysis", Economics of Education Review, Vol.22, pp. 89-97.

Ahmadi-Esfahani, F.Z. and Locke, C.G. (1998), "Wholesale food markets with 'Chinese characteristics"', Food policy, Vol.23 No.1, pp. 89-103.

Balaguer-Coll, M.T., Prior, D. and Tortosa-Ausina, E. (2007), "On the determinants of local government performance: A two-stage nonparametric approach", European Economic Review, Vol.51 No.2, pp. 425-451.

Beijing Statistical Information Net. (2014). "Beijing Statistics Yearbook 2013”, available at: http://www.bjstats.gov.cn/ (accessed 24 September 2014).

Carr, A.S. and Pearson, J.N. (1999), "Strategically managed buyer-supplier relationships and performance outcomes", Journal of Operations Management, Vol. 17 No. 5, pp, 497-519.

Charnes, A., Cooper, W.W. and Rhodes, E. (1978), "Measuring the efficiency of decision making units", European Journal of Operational Research, Vol. 2 No. 6, pp, 429-444.

Chen, B., An, Y. and Liu, Y. (2006), "Target model and priority in upgrading China's agro-food wholesale market”, Agricultural Economics, Vol. 5, pp, 107-110.

Coelli, T.J. (1996), “A Guide to DEAP Version 2.1: A Data Envelopment Analysis (Computer) Program”, CEPA Working Papers, University of New England, Armidale, August.

Coelli, T.J., Rao, D.S.P., O'donnell, C.J. and Battese, G.E. (1998), An introduction to efficiency and productivity analysis, Springer Science and Business Media, Inc, New York.

Coelli, T., Rahman, S., Thirtle, C. (2002), "Technical, allocative, cost and scale efficiencies in Bangladesh rice cultivation: a non-parametric approach", Journal of Agricultural Economics, Vol. 53 No. 3, pp, 607-626.

Conroy, S.J.and Arguea, N.M. (2008), "An estimation of technical efficiency for Florida public elementary schools", Economics of Education Review, Vol. 27 No. 6, pp, 655-663.

Farrell, M.J. (1957), "The measurement of productive efficiency", Journal of the Royal Statistical Society, Vol.120 No. 3, pp, 253-290.

Fluvià, M., Garriga, A., Rigall-I-Torrent, R. and Rodríguez-Carámbula, E. (2012), "Buyer and seller behavior in fish markets organized as Dutch auctions: evidence from a wholesale fish market in Southern Europe”, Fisheries Research, Vol. 127-128, pp, 18-25.

Fraser, I. and Cordina, D. (1999), "An application of data envelopment analysis to irrigated dairy farms in Northern Victoria”, Agricultural Systems, Vol. 59 No. 3, pp, 267-282.

Galanopoulos, K., Aggelopoulos, S., Kamenidou, I. and Mattas, K. (2006), "Assessing the effects of managerial and production practices on the efficiency of commercial pig farming", Agricultural systemsm, Vol. 88 No. 3, pp, 125-141.

Gallegati, M., Giulioni, G., Kirman, A. and Palestrini, A. (2011), "What's that got to do with the price of fish? Buyers behavior on the Ancona fish market", Journal of Economic Behavior \& Organization, Vol. 80, pp, 20-33.

Gillen, D. and Lall, A. (1997), "Developing measure of airport productivity and performance: an 
application of data envelopment analysis”, Transpn Res.-E, Vol. 33 No. 4, pp, 261-273.

Giménez, V., Prior, D. and Thieme, C. (2007), "Technical efficiency, managerial efficiency and objective-setting in the educational system: an international comparison", Journal of the Operational Research Society, Vol. 58 No. 8, pp, 996-1007.

Giulioni, G. and Bucciarelli, E. (2011). "Agents' ability to manage information in centralized markets: comparing two wholesale fish markets", Journal of Economic Behavior \& Organization, Vol. 80, pp, 34-49.

Giulioni, G and Bucciarelli, E. (2008), "Understanding the price dynamics of a real market using simulations: the dutch auction of the Pescara wholesale fish market”, In: Schredelseker, K. (Ed.), Complexity and Artificial Markets, Springer, Leipzig, pp. 15-26.

Gobillon, L. and Wolff, F. and Guillotreau, P. (2013), "The anatomy of prices on the French fish market”, working paper, Paris School of Economics, Paris, June.

Graddy, K. and Hall, G. (2009), "A dynamic model of price discrimination and inventory management at the Fulton Fish Market", working paper, Brandeis University, Waltham, May.

Greene, W.H. (2002), Econometric Analysis, Prentice Hall, Englewood Cliffs, New Jersey.

Guillotreau, P. and Jime'nez-Toribio, R. (2006), "The impact of electronic clock auction systems on shellfish prices: econometric evidence from a structural change model", Journal of Agricultural Economics, Vol. 57 No. 3, pp, 523-546.

Guillotreau, P. and Jime'nez-Toribio, R. (2011), "The price effect of expanding fish auction markets”, Journal of Economic Behavior \& Organization, Vol. 79, pp, 211-225.

Han, Y. and Yang, J. ( 2010), "On the wholesaler-dominated alliance of supply chain in agricultural goods", Journal of Beijing Technology and Business University, Vol. 25 No. 3, pp, 27-31.

Hansson, H. and Öhlmér, B. (2008), "The effect of operational managerial practices on economic, technical and allocative efficiency at Swedish dairy farms", Livestock Science, Vol. 118 No. 1, pp, $34-43$.

Herr, A. (2008), "Cost and technical efficiency of German hospitals: Does ownership matter?", Health Economics, Vol. 17 No. 9, pp, 1057-1071.

Iráizoz, B., Rapún, M. and Zabaleta, I.(2003), "Assessing the technical efficiency of horticultural production in Navarra, Spain”, Agricultural systems, Vol. 78 No. 3, pp, 387-403.

Jiao, W., Fu, Z., Mu, W, Mclaughlin, N. and Xu, M. (2012), "Influence of supply chain model on quality and safety control of table grape and performance of small-scale vinegrowers in China", British Food Journal, Vol.114 No.7, pp. 978-996.

Jin, S. (2007), "Research on construction of modern agricultural product market system", working paper, Huazhong Agricultural University, Wuhan, June.

Kannan, V.R. and Tan, K.C. (2006), "Buyer-supplier relationships", International Journal of Physical Distribution \& Logistics Management, Vol. 36 No. 10, pp, 755-775.

Kim, Y.D. and Yoon, S. (2009), "A note on the improvement of evaluation system in wholesale markets of agricultural and fishery products", American Journal of Applied Sciences, Vol. 6 No. 8, pp, 1604-1612.

Kou, R. and Tan, X. (2008), “Analysis of vegetable wholesaler' efficiency in China”, China Rural Survey, Vol. 2, pp, 2-12.

Kirman, A. Hardle, W. Schulz, R. and Werwatz, A. (2002), "Transactions that did not happen and their influence on prices", working paper, School of Business and Economics, Berlin, June.

Lee, T., Kao, J. and Wu, C. (2002), "Application of PDSS to improve the pricing efficiency of 
wholesale fish markets", Simulation Practice and Theory, Vol. 9, pp, 241-253.

Li, Z., Mi, X. and An, Y. (2013), "Fuzzy analysis of the efficiency of the nonprofit agricultural product wholesaler markets construction funds", Economic Problems, Vol. 10 , pp, 99-102.

Liu, S.-T. (2010), "Measuring and categorizing technical efficiency and productivity change of commercial banks in Taiwan", Expert Systems with Applications, Vol. 37 No. 4, pp, 2783-2789.

Liu, W. and An, Y. (2010). "Economic nature measurement of agricultural product wholesale markets based on function separation", Research on Economics and Management, Vol. 10, pp, 83-88, 114.

Liu, W., an. Y. and Zhang, H. (2011), "Trend of Chinese wholesale markets for agricultural products", Rural Economics, Vol. 4, pp, 11-14.

Meulenberg, M.T.G. (2000). "Voluntary Marketing Institutions in Food Marketing Systems". In: Tilburg, A. van., Moll, H. A. J. and Kuyvenhoven, A. (Eds.), Agricultural Markets Beyond Liberalization, Kluwer Academic Publishers, Boston, pp. 213-233.

Ministry of Agriculture of the People's Republic of China Net. (2011). "The Chinese Wholesale Market Development Report", available at: http://www.moa.gov.cn/sjzz/scs/sclt/201106/t20110606_2008211.htm (accessed 31 July 2014).

Mukhtar, T. and Javed, M.T. (2008), "Market integration in wholesale Maize markets in Pakistan", Regional and Sectoral Economic Studies, Vol. 8 No. 2, pp. 85-98.

National Bureau of Statistics of China. (2014). "China Statistical Yearbook 2013", available at: http://data.stats.gov.cn/workspace/index?m=hgnd (accessed 26 October 2014).

Pasiouras, F. (2008), "International evidence on the impact of regulations and supervision on banks' technical efficiency: An application of two-stage data envelopment analysis", Review of Quantitative Finance and Accounting, Vol. 30 No. 2, pp. 187-223.

Paxton, J. (2007), "Technical efficiency in a semi-formal financial sector: The case of Mexico", Oxford Bulletin of Economics and Statistics, Vol. 69 No. 1, pp. 57-74.

Perrigot, R. and Barros, C.P. (2008), "Technical efficiency of French retailers". Journal of Retailing and Consumer Services, Vol. 15 No. 4, pp, 296-305.

Rawwas, M.Y.A., Konishi, K., Kamise, S. and Al-Khatib, J. (2008), "Japanese distribution system: The impact of newly designed collaborations on wholesalers' performance", Industrial Marketing Management, Vol. 37 No. 1, pp. 104-115.

Reardon, T. and Berdegué, J. A. (2002), "The Rapid Rise of Supermarkets in Latin America: Challenges and Opportunities for Development", World Development, Vol. 20 No. 4, pp, 371-388.

Ren, Y. and An, Y. (2010), "Efficient food safety regulation in the agro-food wholesale market", Agriculture and Agricultural Science Procedia, Vol. 1, pp, 344-353.

Sellers-Rubio, R., Más-Ruiz, F.J. (2009), "Technical efficiency in the retail food industry: The influence of inventory investment, wage levels, and age of the firm", European Journal of Marketing, Vol. 43 No. 5-6, pp. 652-669.

Somogyi, S., Gyau, A., Li Elton. and Bruwer, J. (2010), "Enhancing long-term grape grower/winery relationships in the Australian wine industry", International Journal of Wine Business Research, Vol. 22 No. 1, pp. 27-41.

Stringer, R., Sang, N. and Croppenstedt, A. (2009), "Producers, Processors, and Procurement Decisions: The Case of Vegetable Supply Chains in China", World Development, Vol. 37 No. 11, pp. 1773-1780. 
Vignes, A. and Etienne, J. (2011), "Price formation on the Marseille fish market: Evidence from a network analysis", Journal of Economic Behavior \& Organization, Vol. 80, pp. 50-67.

Wang, J. (2007), "Countermeasures of Chinese wholesale market development", working paper, Beijing Jiaotong University, Beijing, June.

Zhang, H., Sun, Q. and An, Y. (2009), "Efficiency evaluation for wholesale markets for agriculture products in China", Chinese Rural Economy, Vol. 10, pp. 51-57.

Zhao, H. (2009), "Problems and policies of agricultural wholesale markets in China", Modern Business, Vol. 9, pp. 10-11.

Zhu, J. (2006), "Measuring Competitiveness of Wholesale Markets: Theory, Methods and Applications", Journal of Agrotechnical Economics, Vol.1, pp. 53-61.

USDA. (2014), "Fresh Grape Production, Supply, and Distribution", available at: http://apps.fas.usda.gov/psdonline/(accessed 14 September 2014). 